\title{
Ghost fishing in the pot fishery for blue swimmer crabs Portunus pelagicus in Queensland, Australia ${ }^{\text {th }}$
}

\author{
Matthew J. Campbell*, Wayne D. Sumpton \\ Queensland Department of Primary Industries and Fisheries, Southern Fisheries Centre, P.O. Box 76 Deception Bay, Queensland 4508, Australia
}

\section{A R T I C L E I N F O}

\section{Article history:}

Received 7 April 2008

Received in revised form

11 September 2008

Accepted 16 September 2008

\section{Keywords:}

Blue swimmer crab

Ghost fishing

Pot fishery

Portunus pelagicus

Collapsible pot

Escape

\begin{abstract}
A B S T R A C T
Blue swimmer crabs (Portunus pelagicus) are an economically important crab caught in baited traps throughout the Indo-west Pacific and Mediterranean. In Australia they are traditionally caught using rigid wire traps ( $\approx$ pots) but there has been a recent increase in the use of collapsible pots constructed from polyethylene trawl mesh. Two experiments were conducted in Moreton Bay, Queensland, to determine the ghost fishing potential of lost crab pots on both target and bycatch species and to evaluate the differences between traditional and contemporary pot designs. A lost contemporary, collapsible trawl mesh pot will catch between 3 and 223 P. pelagicus per year after the bait has been exhausted, while a traditional wire mesh pot would catch 11-74 crabs per year. As most fishers now use the collapsible trawl mesh pots, ghost fishing mortality could be as high as 111,811-670,866 crabs per year. Bycatch retention was also higher in contemporary designs. Periods of strong winds appeared to increase the ghost fishing potential of lost pots. The use of escape gaps, larger mesh sizes and construction options that allow for the deterioration of entrance funnels to minimise ghost fishing are recommended to reduce environmental impacts.
\end{abstract}

Crown Copyright @ 2008 Published by Elsevier B.V. All rights reserved.

\section{Introduction}

The blue swimmer crab Portunus pelagicus is the basis of a valuable commercial and recreational fishery in Australia and elsewhere throughout the Indo-west Pacific and Mediterranean Oceans (Kailola et al., 1993). The species is taken as bycatch by trawl fishers but a significant amount is landed by fishers using baited traps (colloquially known as pots in Australia). Total landings of blue swimmer crabs in 2005 from the commercial pot fishery in Queensland was approximately 800 tonnes, worth about \$AU6.4 million.

In Queensland, the majority of the effort in the fishery is restricted to the area between Moreton Bay $\left(27^{\circ} 15^{\prime} \mathrm{S}, 153^{\circ} 15^{\prime} \mathrm{E}\right)$ and Bundaberg $\left(24^{\circ} 45^{\prime} \mathrm{S}, 152^{\circ} 25^{\prime} \mathrm{E}\right)$, in both inshore and offshore grounds. A mixture of adult and sub-adult animals typifies the inshore fishery ( $<20 \mathrm{~m}$ depth), while large adult males dominate the offshore fishery. Only male crabs greater than $11.5 \mathrm{~cm}$ carapace width (measured between the notches just forward of the lateral spines) are allowed to be retained. Fishers generally fish from vessels approximately $8 \mathrm{~m}$ in length, up to a maximum of $14 \mathrm{~m}$, with each licence holder limited to 50 pots. Typically, fishers set their pots on individual buoyed lines in the shallower inshore grounds

\footnotetext{
is The State of Queensland, Department of Primary Industries and Fisheries (2008).

* Corresponding author. Tel.: +61 73817 9591; fax: +61 738179555

E-mail address: matthew.campbell@dpi.qld.gov.au (M.J. Campbell).
}

$(<20 \mathrm{~m})$. In offshore waters, pots are set in trotlines of about ten pots deployed with buoys at either end of the line. Baited pots are usually left to fish in the water continuously and are commonly cleared and rebaited daily, most commonly with a single $\approx 500$-g sea mullet (Mugil cephalus), although inclement weather conditions can prevent fishers from tending pots for up to 10 days. This is particularly the case in the offshore fishery during summer when south-easterly trade winds regularly reach 25 knots or more.

Traditionally, Queensland fishers used rigid pots constructed from a steel rod frame, covered by wire meshing (Smith and Sumpton, 1989). In the late-1980s, however, some fishers began using pots constructed of multi-filament, polyethylene trawl mesh ( $\approx 50 \mathrm{~mm}$ diamond-shaped mesh) on a steel and/or plastic frame. Approximately 95\% of fishers operating in the Moreton Bay area are now using these trawl mesh pots (Wayne Sumpton, unpublished data). This trend occurred for a number of reasons. Firstly, trawl mesh pots are less prone to corrosion, thereby prolonging the effective working life of the gear. Secondly, some trawl mesh pots are collapsible and allow for easy storage aboard small vessels enabling fishers to work more efficiently when fishing further from port. Also, fishers believe that they achieve higher catch rates and are less prone to sea turtle interactions when compared with the traditional wire mesh pots.

A recent survey of Queensland's commercial crab fishers (Sumpton et al., 2003) reported that significant pot loss occurred during a fishing season. Annual pot losses of 35 pots per year per fisher were reported or in excess of 6000 pots for the entire fish- 
ery, about half of which remain in the environment. According to the fishers, pot loss occurred for several reasons including the accidental or intentional removal of marker floats and pots by other vessels, heavy weather moving pots into deeper water and incidental removal of floats by large animals including sharks. Regardless of the reasons for the loss, gear remaining in the environment gives rise to ghost fishing, a phenomenon described by Smolowitz (1978a) as the ability of fishing gear to continue fishing after all control of that gear is lost by the fisherman. Theoretically, ghost fishing occurs when the contents of a lost pot (both target species and bycatch) die and attract more animals into the pot. These animals then die and attract more, with this process continuing until the pot breaks down and can no longer fish.

Historically, a lost traditional wire mesh pot would corrode and cease fishing in a relatively short space of time and fishers commonly replaced the wire mesh at least once per fishing season (Sumpton et al., 2003). However, the more durable nature of a trawl mesh pot is that, if lost, it will remain viable for a longer period of time and may continue to ghost fish for crabs and bycatch species long after the traditional wire designs would have corroded away. Further, the shift toward the use of trawl mesh pots, with smaller mesh sizes, may have resulted in higher retention rates of smaller bycatch species.

The objective of this study was to examine the ghost fishing characteristics of the traditional wire mesh pot compared to the contemporary collapsible and rigid-framed trawl mesh pots, used by commercial crab fishers. Specifically, the rates of entrance, escapement and mortality of the target species are assessed and the bycatch composition of each pot type is described. The overall pot loss in the fishery is quantified and the ecological impacts of ghost fishing are discussed along with mitigation strategies.

\section{Materials and methods}

Two ghost fishing experiments were conducted in Deception Bay, part of the larger Moreton Bay, Queensland $\left(27^{\circ} 11^{\prime} \mathrm{S} 153^{\circ} 03^{\prime} \mathrm{E}\right)$. The area is generally shallow $(<10 \mathrm{~m})$ with a mud/silt substrate with high turbidity throughout the windy autumn and summer months. This area was chosen for the experiment as it is easily accessible in most weather conditions and there is a substantial P. pelagicus population that is fished throughout the year by both recreational and commercial fishers.

Three pot designs that are used by commercial fishers were used in the experiments. The first design tested was the traditional wiremesh pot $(930 \mathrm{~mm}$ diameter, $300 \mathrm{~mm}$ high). The frame consists of two circular $6 \mathrm{~mm}$ galvanised steel hoops, held apart by four evenly spaced $6 \mathrm{~mm}$ galvanised steel rod uprights. The frame was covered by hexagonal-shaped $1 \mathrm{~mm}$ galvanised steel mesh (mesh size approximately $60 \mathrm{~mm}$ ). Two diametrically opposed, inclined entrance funnels each had a rigid galvanised steel rod frame $(2 \mathrm{~mm}$ diameter approximately $250 \mathrm{~mm}$ wide and $60 \mathrm{~mm}$ high) on the inner margin to ensure the correct opening width was maintained during fishing. A hinged, square-shaped access hatch (approximately $25 \mathrm{~cm}$ by $30 \mathrm{~cm}$ ) on one side of the pot allows access to the contents. This pot was described by Smith and Sumpton (1989) and was similar to that used by Miller (1978).

The second pot tested was a contemporary, rigid-framed trawl mesh pot. This pot utilised a frame constructed in the same manner as the traditional wire mesh pot but was $400 \mathrm{~mm}$ high. The frame was covered in \#36-ply polyethylene, diamond-shaped trawl mesh with a mesh size of $50 \mathrm{~mm}$. As with the above pot, two slightly inclined, diametrically opposed entrance funnels (inner funnel margin approximately $300 \mathrm{~mm}$ wide by $40 \mathrm{~mm}$ high) were sewn into the sides of each pot, held open by U-shaped hooks connected through the middle of the pot with rubber shock or "bungy" cord. A drawstring arrangement on the upper side of the pot is utilised to allow access to the pot contents.

The third pot tested was a contemporary, collapsible trawl mesh pot. This pot consisted of two galvanised steel rings ( $8 \mathrm{~mm}$ rod), with a diameter of $1 \mathrm{~m}$, which are threaded through a "tube" of trawl mesh (\#36-ply polyethylene mesh with $50 \mathrm{~mm}$ mesh size). One end of the tube was drawn together and tied-off with $5 \mathrm{~mm}$ multifilament polyethylene twine to form the base (i.e., ventral side) of the pot. A drawstring arrangement is used on the dorsal side of the pot to allow access to the contents. The two rings are held apart using four lengths of plastic (PVC) irrigation pipe, $25 \mathrm{~mm}$ in diameter and approximately $400 \mathrm{~mm}$ each in length, termed uprights. A small hole is drilled approximately $15 \mathrm{~mm}$ from each end of each upright, before a $\mathrm{V}$-shaped notch is cut from the end of each upright to the hole drilled earlier. This allows the uprights to be slipped onto the rings so that the rings fit securely into the pre-drilled holes. The uprights can be removed and the pots collapsed for easy storage. Entrance funnels are the same as those used in the rigid-framed trawl mesh pots described above.

Each pot was attached to a $15-\mathrm{cm}$ diameter spherical float via $5 \mathrm{~m}$ of $6 \mathrm{~mm}$ polyethylene rope. Five pots of each design were deployed alternately, $50 \mathrm{~m}$ apart, in approximately $3 \mathrm{~m}$ of water in the study area with funnels in approximately the same orientation to the tidal flow in order to reduce variation in catch rate due to this factor.

The first experiment was conducted over a period of 46 days beginning on the 15 May 2000. Pots were checked daily for the first 4 days, twice weekly during the following 2 weeks and weekly thereafter. The second experiment was conducted over 78 days beginning on 19 October 2001. During this experiment the pots were checked daily for 3 days, twice the following week and weekly for the remainder of the experiment. In both experiments, the pots were baited once only at the beginning of the experiment with a single frozen sea mullet (Mugil cephalus) weighing approximately $600 \mathrm{~g}$, using stainless steel $(2 \mathrm{~mm}$ rod) baiting wires attached in the centre of each pot's base. When pots were checked they were removed from the water and all $P$. pelagicus were measured, sexed and fitted with a tag. The tags consisted of a numbered, $15 \mathrm{~mm}$ diameter, stainless steel disc that was attached across the lateral spines of the carapace using stainless steel wire. The tag number and carapace width of each individual was noted, as was bycatch abundance and composition, before all animals were returned to the pots. The pots were then returned to the water, with any remaining bait left in situ.

On subsequent lifts, all tagged crabs and bycatch species were noted, while new crabs were tagged, sexed and measured. All captured animals, alive and dead, were left in the pots and records kept of the number of 'new', 'escaped' or 'dead' crabs as well as dead bycatch. The live crabs tagged on previous lifts were classified as 'static'. The crabs were assumed to have entered the pots on the day they were first tagged, while dead crabs were assumed to have died the day they were first discovered dead. Any damage to pots was recorded but was not repaired in order to best replicate the condition of a lost pot.

The condition of the bait was defined as follows. "Fresh" bait was defined as the first 2 days after the pot was first set, "Stale" was from day 2 to day 4 when there was commonly some bait remaining in the pot and "None" referred to day 4 onward when the bait was always exhausted. During the second experiment a further state was described as "None + SE" which was defined as the period after which the bait was exhausted but immediately following an prolonged period of strong ( $>25$ knots) south-easterly winds which occurred during this experiment.

A generalised linear model (GLM) was used to analyse the catch rates of crabs. The catch rate of crabs (in crabs per pot per day) 
was analysed using a step-forward regression model incorporating a normal distribution with a square-root link function using various combinations of known factors including experiment number ( 1 or 2 ), pot type (traditional wire mesh pot, rigid-framed trawl mesh pot and collapsible trawl mesh pot), bait condition (Fresh, Stale, None and None + SE, as described above) and lift number (1-15). Similarly, a step forward regression model using a binomial distribution and logit link function was used to analyse the effects of the above factors on the escapement and mortality of blue swimmer crabs. GLM's were also used to determine if: (a) the size ( $\mathrm{mm}$, carapace width) of crabs entering the pots varied depending on pot type; (b) there was any difference in the size of the crabs that escaped compared to those that died; (c) there was any difference in the size of crabs that entered the pots compared to those that escaped or died.

The potential number of crabs caught by lost pots in the southeast Queensland P. pelagicus fishery was estimated using information gathered during a survey of commercial crab fishers (Sumpton et al., 2003). The results of this survey provided an estimate of the number of pots that are lost throughout a season and the type of pot lost. The number of pots lost per annum was then multiplied by the ghost fishing rates achieved by the collapsible trawl mesh pots and the traditional wire mesh pots in this study to estimate the potential impact of pot loss on the fishery.

\section{Results}

All pots remained structurally sound in both experiments, with only slight corrosion occurring on two of the traditional wire mesh pots during Experiment 2. All pots showed signs of being partially buried in bottom sediments, with considerable amounts of silt observed around the base of all pots. One traditional wire mesh pot was lost, probably stolen, between the 12th and 13th lift during Experiment 2. All observations from this pot were excluded from the analysis.

During Experiment 1, the rigid-framed trawl mesh pots caught significantly $(P<0.001)$ more crabs than the other pot types (Fig. 1$)$, while the crab catch rate in traditional wire mesh pots and the collapsible trawl mesh pots did not differ significantly $(P=0.763)$.

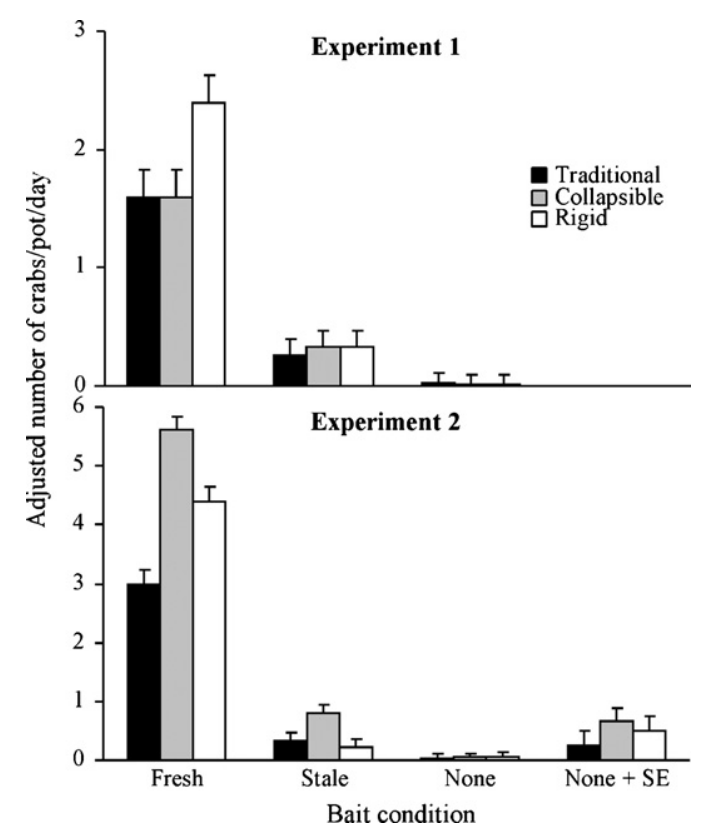

Fig. 1. Adjusted catch rate of $P$. pelagicus caught per pot per day in traditional wire mesh pots (Traditional), collapsible trawl mesh pots (Collapsible) and rigid-framed trawl mesh pots (Rigid) during Experiments 1 and 2.

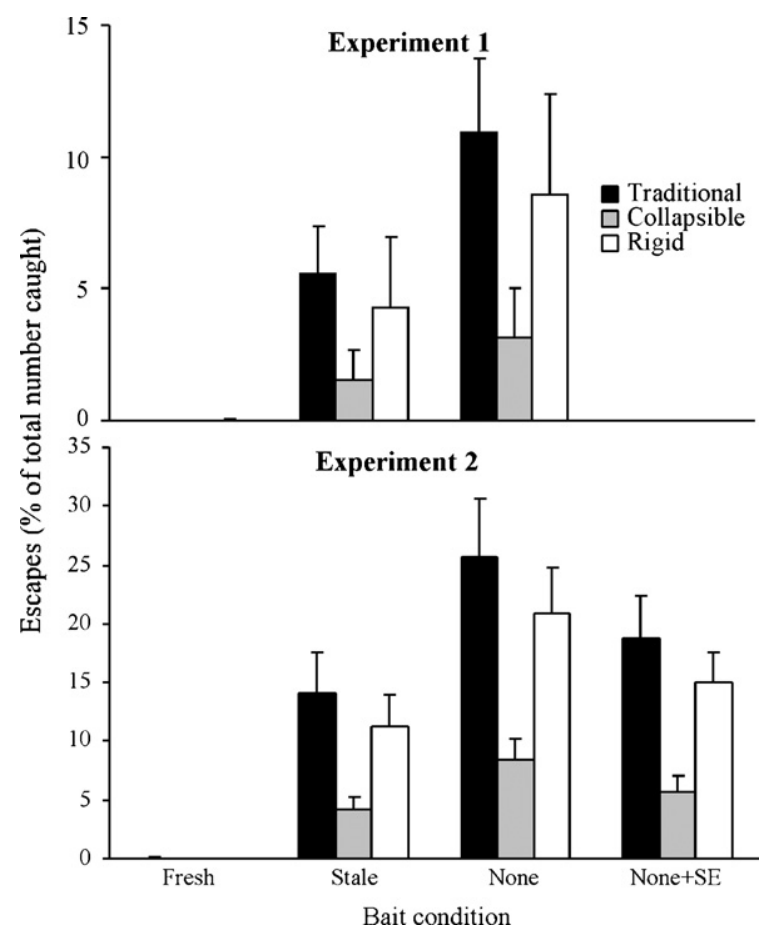

Fig. 2. Adjusted escapement rate of $P$. pelagicus as a percentage of the total number of crabs caught in traditional wire mesh pots (Traditional), collapsible trawl mesh pots (Collapsible) and rigid-framed trawl mesh pots (Rigid) during Experiments 1 and 2 .

In Experiment 2, the collapsible trawl mesh pots caught significantly more $(P<0.001)$ crabs than the rigid-framed trawl mesh pots which, in turn, caught significantly more crabs than the traditional wire mesh pots $(P=0.008)$. As expected, catch rates decreased once the original bait had aged. Further reductions in catch rates were observed after the bait had been exhausted but all pot types continued to catch crabs during this period. During Experiment 2, 5 days of strong ( $>25$ knots) south-easterly winds resulted in increased crab catch rates for all pot types.

We assumed an individual crab had escaped if there was no sign of the carapace and/or the tag and crabs were only classified as "dead" if the carapace and/or tag were present. As such, very few crabs escaped during the initial 2-4 days (Fig. 2). In both experiments, escape rates increased once the bait became stale and were maximised once the bait had been exhausted after 4 days (Bait condition, $P<0.001$ in model). Escapement was significantly lower in the collapsible trawl mesh pots $(P<0.001)$ during both experiments and highest from the traditional wire mesh pots. The traditional wire mesh pots and rigid-framed trawl mesh pots exhibited statistically similar rates of escapement in both experiments (i.e., $P>0.05$ ). During Experiment 2, approximately 27\% of captured crabs escaped from the traditional wire mesh pots, the highest rates of escapement predicted by the GLM.

The number of crab mortalities was very low during initial pot lifts (Fig. 3). In both experiments, most deaths occurred after the bait had been exhausted (after 4 days). Crabs caught in rigidframed trawl mesh pots had significantly higher levels of mortality than those in the collapsible trawl mesh pots $(P=0.004)$ in Experiment 1 , while significantly less mortality occurred in rigid-framed trawl mesh pots compared to the other two designs $(P<0.001)$ in Experiment 2. Once crabs died they quickly decayed or were eaten, typically within the first week (Fig. 4). During Experiment 2, the rate of removal (i.e., the animal was completely eaten or had decayed and no part of the animal was visible) was even greater during the 


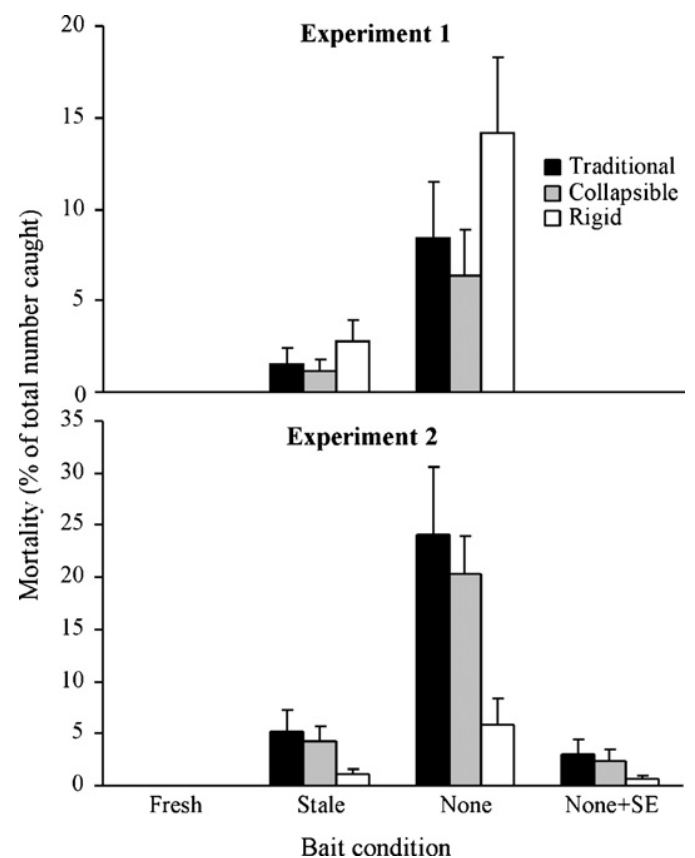

Fig. 3. Adjusted mortality rate of $P$. pelagicus as a percentage of the total number of crabs caught in traditional wire mesh pots (Traditional), collapsible trawl mesh pots (Collapsible) and rigid-framed trawl mesh pots (Rigid) during Experiments 1 and 2.

first week, with $83.6 \%$ of the dead crabs being completely eaten or decayed within a week of being found dead.

The size of the crabs that entered the pots during both experiments was not significantly affected $(P>0.05)$ by pot type despite the difference in mesh size. There was no significant difference $(P>0.05)$ in the carapace width of the crabs that were caught compared to those that escaped from, or died in, all pot types in both experiments. In contrast, the size of the crabs that escaped from each pot type were significantly $(P<0.05)$ smaller than those that died in each pot type in both experiments.

Over the course of the two experiments, more P. pelagicus were caught than any other species, with relatively few recreationally or commercially important bycatch species retained in any of the pot designs (Table 1). Both the collapsible trawl mesh pots and the rigidframed trawl mesh pots retained more bycatch than the traditional wire mesh pots (Table 2 ). The majority of bycatch species observed in the trawl mesh pots were teleost fish such as leatherjackets (Paramonacanthus spp.), toadfish (Marilyna spp.) and trumpeter (Pelates spp.).

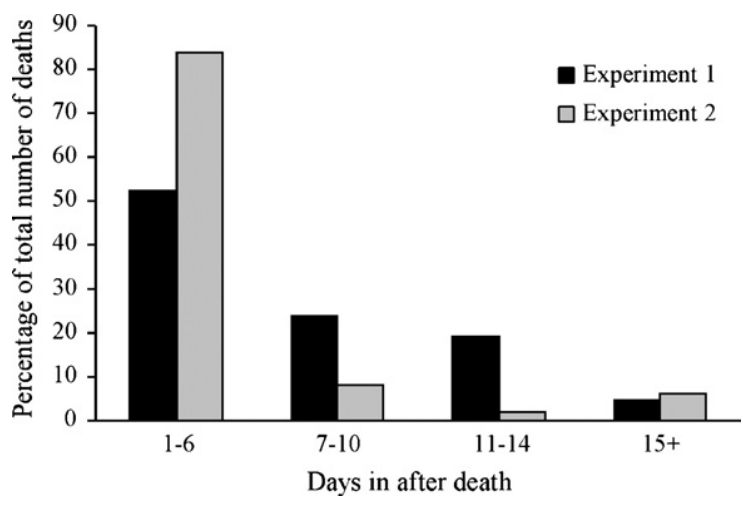

Fig. 4. Number of days after death before dead P. pelagicus were completely removed (i.e., the animal was completely eaten or had decayed and no part of the animal was visible) as a percentage of the total number of dead crabs.
Using the crab catch and escapement rates achieved during these experiments, combined with the range of estimates of pot loss in the commercial fishery reported by Sumpton et al. (2003), it was possible to estimate the number of $P$. pelagicus that are caught by ghost fishing pots (Table 3 ). The ghost fishing rates achieved by the collapsible trawl mesh pots range from 1733 to 670,866 crabs per year, while the traditional wire mesh pots would catch between 4138 and 222,434 crabs per year, if they were still widely used by commercial fishers.

\section{Discussion}

The two experiments reinforce the commercial fishers' belief about the benefits of using collapsible trawl mesh pots over the traditional wire mesh design. From Fig. 1, both the collapsible trawl mesh pots and rigid-framed trawl mesh pots caught more P. pelagicus than the traditional wire mesh pots. Several studies, including Guillory and Prejean (1997) and Vazquez Archdale and Kuwahara (2005), have shown that pots with larger mesh sizes catch fewer crabs with an increase in mean size, when compared to pots with smaller mesh sizes. In the current study, the traditional wire mesh pots, with a larger mesh size, did catch fewer crabs but also caught the smallest crabs in Experiment 1 compared to the trawl mesh pot designs. In Experiment 2, the traditional wire mesh pots caught fewer crabs than the trawl mesh pot designs but also caught smaller crabs than the rigid-framed trawl mesh pots (Table 1). Although it is difficult to determine why this result differed significantly from previous studies, escapement was highest from the traditional wire mesh pots during both experiments and smaller crabs may have escaped before the pots were lifted, particularly during the "zero bait" stages. This is further evidenced by Smith and Sumpton (1989), who observed a small female P. pelagicus, with a carapace width of $118 \mathrm{~mm}$, escape from a traditional wire mesh pot through the mesh rather than out of a funnel. This probably contributed to the lower catch rates of the traditional wire mesh pots and also explains the relatively large average carapace width in crabs caught in the traditional wire mesh pots. Zhou and Shirley (1997), working on Paralithes camtschaticus, state that a mesh size smaller than chela size may motivate crabs to search around a pot and increase the probability of finding an entrance. As such, it could have been expected that the trawl mesh pots would not only catch more crabs but also catch smaller crabs than the traditional wire mesh pots. This, as stated above, was not the case and suggests that $P$. pelagicus and P. camtschaticus may exhibit differing behaviours when encountering a pot.

Guillory and Hein (1998) observed differing catch rates from pots that are manufactured using hexagonal mesh, compared to pots constructed from square mesh. It is difficult to comment on the differences in using hexagonal wire mesh over the diamondshaped trawl mesh in the present study as both the materials used and the mesh size differ between pot types. As such, these factors were not independent of pot type and their effects could not be isolated. The isolation of single design parameters is difficult and this has been discussed by Vazquez Archdale and Kuwahara (2005), however, the effects of the size, shape and material of the mesh used on ghost fishing in Queensland's P. pelagicus fishery should be considered in further studies.

Not only did the trawl mesh pots achieve higher catch rates than the traditional wire mesh pots in both experiments, but they also retained a higher proportion of caught crabs. The rates of escapement of $P$. pelagicus are significantly lower than the Dungeness crabs Cancer magister as observed by Muir et al. (1984), who stated that $60 \%$ of captured crabs escaped from commercial pots in the Columbia River in north-western USA. High (1976) reported that $74 \%$ of $C$. magister escaped from cylindrical pots with open entrance 
Table 1

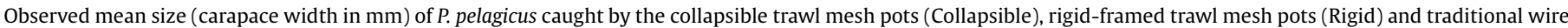
mesh pots (Traditional) during Experiments 1 and 2. Standard errors are shown in parenthesis.

\begin{tabular}{|c|c|c|c|c|c|c|}
\hline & \multicolumn{3}{|l|}{ Experiment 1} & \multicolumn{3}{|l|}{ Experiment 2} \\
\hline & Collapsible & Rigid & Traditional & Collapsible & Rigid & Traditional \\
\hline Ratio males to females & 3.67 & 1.57 & 4.50 & 2.00 & 1.12 & 1.55 \\
\hline Mean size of crabs caught & $130.64(2.50)$ & $129.44(4.63)$ & $128.77(3.93)$ & $135.78(1.73)$ & $139.64(1.94)$ & $137.26(1.68)$ \\
\hline Mean size of escaped crabs & $128.50(0.50)$ & $129.33(7.93)$ & $122.29(4.18)$ & $132.43(4.33)$ & $138.43(2.72)$ & $134.5(1.94)$ \\
\hline Mean size of dead crabs & $131.33(2.97)$ & $132.00(2.42)$ & $133.1(4.02)$ & $135.21(2.75)$ & $144.2(2.19)$ & $142.67(6.23)$ \\
\hline
\end{tabular}

Table 2

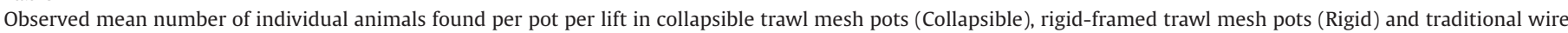
mesh pots (Traditional) during Experiments. Standard errors are shown in brackets. Species of recreational (R) or commercial (C) importance are also highlighted.

\begin{tabular}{|c|c|c|c|c|c|c|}
\hline \multirow[t]{2}{*}{ Species } & \multicolumn{3}{|l|}{ Experiment 1} & \multicolumn{3}{|l|}{ Experiment 2} \\
\hline & Collapsible & Rigid & Traditional & Collapsible & Rigid & Traditional \\
\hline \multicolumn{7}{|l|}{ Fish } \\
\hline Apogon spp. & $0.033(0.023)$ & $0.017(0.017)$ & 0 & - & - & - \\
\hline Euristhmus spp. & - & - & - & $0.073(0.029)$ & 0 & 0 \\
\hline Lutjanus spp. (R/C) & $0.133(0.044)$ & 0 & 0 & - & - & - \\
\hline Marilyna spp. & $0.350(0.078)$ & $0.100(0.046)$ & $0.016(0.016)$ & $2.744(0.491)$ & $0.478(0.146)$ & $0.127(0.024)$ \\
\hline Microcanthus spp. & - & - & - & $0.012(0.012)$ & 0 & 0 \\
\hline Paramonacanthus spp. & $0.450(0.096)$ & $0.050(0.028)$ & 0 & $0.171(0.063)$ & 0 & $0.014(0.014)$ \\
\hline Pelates spp. & $0.350(0.096)$ & $0.183(0.077)$ & 0 & $0.073(0.029)$ & 0 & 0 \\
\hline Pseudorhombus spp. & $0.050(0.028)$ & 0 & 0 & - & - & - \\
\hline Terapon spp. & $0.033(0.033)$ & 0 & 0 & - & - & - \\
\hline Trixiphichthys spp. & 0 & $0.050(0.050)$ & $0.242(0.101)$ & - & - & - \\
\hline \multicolumn{7}{|l|}{ Sharks and Rays } \\
\hline Dasyatis spp. & 0 & 0 & $0.016(0.016)$ & 0 & $0.045(0.041)$ & $0.070(0.068)$ \\
\hline Orectolobus spp. & 0 & 0 & $0.016(0.016)$ & 0 & 0 & $0.014(0.014)$ \\
\hline \multicolumn{7}{|l|}{ Crabs } \\
\hline Charybdis spp. (R/C) & $0.217(0.079)$ & 0 & 0 & $0.061(0.027)$ & $0.119(0.037)$ & $0.0280 .019)$ \\
\hline P. pelagicus (R/C) & $2.367(0.092)$ & $2.317(0.224)$ & $1.581(0.199)$ & $5.683(0.305)$ & $4.090(0.243)$ & $2.282(0.156)$ \\
\hline P. sanguinolentus $(\mathrm{R} / \mathrm{C})$ & $0.267(0.075)$ & 0 & 0 & - & - & - \\
\hline Scylla serrata $(\mathrm{R} / \mathrm{C})$ & $0.233(0.084)$ & $0.133(0.060)$ & $0.194(0.073)$ & $0.110(0.035)$ & $0.149(0.052)$ & $0.085(0.042)$ \\
\hline \multicolumn{7}{|l|}{ Molluscs } \\
\hline Sepia spp. (C) & - & - & - & $0.012(0.012)$ & 0 & 0 \\
\hline
\end{tabular}

funnels fitted with non-functioning triggers. High and Worlund (1979) found escape rates of king crabs Paralithes camtschaticus from commercial pots of $92 \%$ for undersize crabs and $80 \%$ for legal crabs. Further, Godøy et al. (2003) reported escape rates as high as $92 \%$ for tagged $P$. camtschaticus from rectangular pots, but also reported escape rates during the same study of 45 and 61\% in separate experiments. As such, the escape rates achieved in the present study are relatively low, especially in the collapsible trawl mesh pots and the rigid-framed trawl mesh pots. Low escapement by $P$. pelagicus was also described by Smith and Sumpton (1989), who observed that only $1.1 \%$ of $P$. pelagicus caught in a traditional wire mesh pot escaped through the entrance funnels during an experi- ment observing crab behaviour in and around traditional wire mesh pots.

For capture and escapement, the design of entrance funnels are an important factor which has been discussed by several authors including Miller (1978), Smith and Sumpton (1989), Zhou and Shirley (1997) and Vazquez Archdale et al. (2006). Captured crabs are less likely to encounter an entrance funnel if it is raised above the pot floor and are, therefore, less likely to escape. A further advantage of a raised funnel is that crabs entering a pot have a competitive advantage over crabs already inside the pot (Miller, 1980; Smith and Sumpton, 1989) and will readily enter pots as they are less likely to be threatened by captured crabs. In both the trawl

Table 3

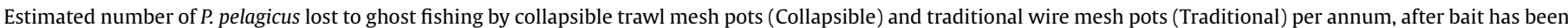

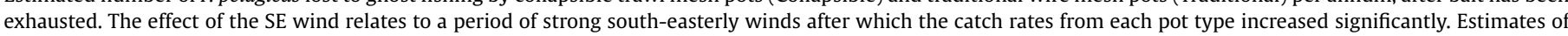
pots lost and left in the environment in Queensland range from 500-3000 (Sumpton et al., 2003).

\begin{tabular}{|c|c|c|c|c|}
\hline Pot type & $\begin{array}{l}\text { Number of crabs } \\
\text { per year ( } 365 \text { days) }\end{array}$ & $\begin{array}{l}\text { Number of crabs } \\
\text { after escapement }\end{array}$ & $\begin{array}{l}\text { Crabs lost to ghost fishing } \\
\text { per year ( } 500 \text { pots) }\end{array}$ & $\begin{array}{l}\text { Crabs lost to ghost fishing } \\
\text { per year ( } 3000 \text { pots) }\end{array}$ \\
\hline \multicolumn{5}{|l|}{ Experiment 1} \\
\hline Traditional & 12.264 & 10.929 & 5,464 & 32,786 \\
\hline Collapsible & 3.577 & 3.465 & 1,733 & 10,395 \\
\hline \multicolumn{5}{|c|}{ Experiment 2 without the effect of the SE wind } \\
\hline Traditional & 11.133 & 8.277 & 4,138 & 24,830 \\
\hline Collapsible & 15.148 & 13.882 & 6,941 & 41,646 \\
\hline \multicolumn{5}{|c|}{ Experiment 2 with the effect of the SE wind } \\
\hline Traditional & 91.25 & 74.145 & 37,072 & 222,434 \\
\hline Collapsible & 237.25 & 223.622 & 111,811 & 670,866 \\
\hline
\end{tabular}


mesh pot designs, the funnels are located further from the base of the pot compared to the traditional wire mesh pot which would contribute to the higher catch rates and lower escapement rates observed by the trawl mesh pots.

The vertical opening of funnels also differed with pot type, which would have contributed to the difference in the observed escapement rates. The terminal height of the funnels in the traditional wire mesh pots was at least $60 \mathrm{~mm}$ compared to $35-40 \mathrm{~mm}$ in both the trawl mesh designs. Further, the terminal end of the funnels in the traditional wire mesh pots were held open by a galvanised steel rod (diameter of $2 \mathrm{~mm}$ ) frame. In comparison, the trawl mesh funnels were flexible and could allow larger animals to enter the pot but would then resume fishing height, preventing easy escape by captured animals. Experiments conducted by Vazquez Archdale et al. (2006) showed that escapement rates were higher in pots incorporating open entrance funnels when compared to funnels constructed with "slit" entrances. The slits effectively acted as a non-return valve, allowing crabs to enter such pots but reducing escapement significantly compared to open-funnelled pots. The current experiment shows that funnel design does contribute to a pots' ability to ghost fish and that, although difficult to isolate their effects, the shape and size of the funnel contributed to the rates of both capture and escape.

Crab mortalities occurred in all pot types, with maximum mortality rates occurring once the bait had been exhausted. The mortality observed rates of $P$. pelagicus are low when compared to results gained elsewhere. Breen (1978) observed a 55\% mortality rate for Cancer magister over 1 year in British Columbia, much higher mortality rates than those observed in the current study. Similarly, Kimker (1994) stated that 39\% of Tanner crabs (Chionoecetes bairdi) died in closed pots in Alaska. Hébert et al. (2001) generated an exponential equation to model mortality of snow crabs (Chionoecetes opilio), which, if applied to the current study would give mortality rates, as a function of time, of $31 \%$ for Experiment 1 and $46 \%$ for Experiment 2 . The two former studies were conducted over a much longer time period (365 days and 120 days, respectively) than the current study which may explain the differences in mortality rates. For example, Kimker (1994) observed a mortality rate of approximately $21 \%$ after 77 days which is very similar to the mortality rates generated during the current experiment. As stated earlier, both experiments in the current study were curtailed due to time constraints and further studies, utilising a longer time series of data, are needed. This is further evidenced by trials conducted by Muir et al. (1984), who observed a $19 \%$ mortality rate of the Dungeness crab Cancer magister over only a 28-day period using similar gear on the same species and the same estuary as Breen (1978), who observed $55 \%$ mortality over 365 days.

No octopi were observed in any pot type and the presence of these animals cannot be proven conclusively. Crab limb loss did occur but was not quantified due to the fact that the extra air exposure may have compromised the integrity of the experiments. We expect that at least some cannibalism did occur and Kimker (1994) suggests that this may mitigate the effects of starvation. Also the larger, more aggressive crab, Scylla serrata, was present in all pot types and would have certainly contributed to P. pelagicus mortality. Most crabs in both experiments stayed in the pots less than a week after being found dead. Frequently, the carapace, with the tag attached, was found but this quickly broke-up leaving only the tag in the pot. Kimker (1994) stated that cannibalism by living Chionoecetes bairdi on dead cohorts broke up the exoskeleton of these crabs and the remains were flushed out of the pot. Further, Kimker (1994) also observed that the carapaces found in the pots were paper thin and fragile. Both of these observations are comparable to the current study. No crabs appeared to have molted during either experiment and whole exoskeletons were not found in any pot.
As the anecdotal evidence suggested, the trawl mesh pots caught more bycatch than the traditional wire mesh pots. It is reasonable to assume that entrance funnel design and the smaller mesh size contributed to the higher catch rates of bycatch when compared to the traditional wire mesh pots. As with crab ingress and escapement, entrance funnel design and mesh size would certainly affect a pots' capacity to firstly catch, and then retain, bycatch species. It is likely that these species attracted more crabs into the pots once they died and can explain the elevated catch rates of $P$. pelagicus after the bait was exhausted. Indeed, the remains of several fish species were regularly observed in pots. The higher catch rates of bycatch species in the collapsible trawl mesh pots may have contributed to the decrease in P. pelagicus mortalities observed in these pots, when compared to the larger-meshed traditional wire mesh pots. That is, as these bycatch species died, captured crabs could feed on the carcasses, thereby avoiding death by starvation. This phenomenon was described by Guillory (1993), who stated that dead fish caught during a ghost fishing experiment in the blue crab (Callinectes sapidus) fishery were quickly consumed by the captured crabs. Further, Bullimore et al. (2001) suspected that fish caught in pots designed to catch brown crabs (Cancer pagurus) and spider crabs (Maja squinado), may provide a source of food for trapped Crustaceans.

Given the results achieved in these experiments, it is clear that the pots used in the $P$. pelagicus fishery ghost fish. Studies in the United States, Europe and Canada have examined ghost fishing by pots in crustacean fisheries (Breen, 1978; Bullimore et al., 2001; Godøy et al., 2003; Guillory, 1993; Hébert et al., 2001; High, 1976; High and Worlund, 1979; Muir et al., 1984; Vazquez Archdale et al., 2007) and have generally found that all types of trapping apparatus ghost fish. Ghost fishing in the Dungeness crab Cancer magister fishery has been investigated by Breen (1978), who recorded a steady increase in the cumulative catch of crabs with an overall average catch rate of 16.9 crabs per pot per year. Ghost fishing in the blue crab, Callinectes sapidus (a species similar to P. pelagicus) fishery in a Louisiana estuary was estimated at 34.9 crabs per pot despite the lack of bait Guillory (1993). An example of the significance of ghost fishing in a crab fishery is provided by Hébert et al. (2001), who stated that 1000 lost conical traps would kill 84,194 snow crabs (Chionoecetes opilio), or 48.2 tonnes, per year.

Based on the average rate of entrance of crabs determined by the current experiments, and excluding the impact of strong wind, a lost pot will catch an average of 15 crabs per annum (range 3-237 crabs), which is comparable to ghost fishing rates in other crab fisheries. However, the dramatic change that occurred after the strong winds in Experiment 2 cannot be discounted, particularly as it increased estimates of ghost fishing by over an order of magnitude. Similar weather events may further increase the rate of entrance of crabs thereby causing the ghost fishing rates estimated in these experiments to be underestimated. The period of strong south-easterly winds resulted in additional entrances of crabs to pots (of all types) where the bait had been exhausted for some time. The rate at which crabs entered pots also increased after this period. For both trawl mesh pots an additional 5 or 6 crabs per pot entered the pots following the period of strong winds. At the same time there was no apparent increase in the amount of fish bycatch in the pots and no noticeable change in the numbers of dead fish. In fact, most pots had no dead fish evident when the increase was observed. Many fishers (e.g., Gary Smith, personal communication) have also commented on elevated catch rates after periods of strong winds. Bullimore et al. (2001) observed a similar increase in the catch rates of brown crabs (Cancer pagurus) and spider crabs (Maja squinado) in pots during a ghost fishing experiment in Wales long after the bait had been exhausted, linking this increase in catch rates to a rise in water temperature. Whether the increase in catch rate was 
due to the rise in water temperature, with the strong winds pushing warmer offshore currents into Moreton Bay or simply the fact that the crabs sort refuge in the pots from the foul weather cannot be proven, but such abiotic factors should be considered in further studies.

There are currently no management regulations to reduce ghost fishing by pots in either the commercial or recreational fishery in Queensland. During a recent survey of recreational fishing, 1.9\% of all recreational anglers interviewed in Queensland targeted $P$. pelagicus, $38 \%$ of which used pots to capture the crabs (Higgs and McInnes, 2003). The remainder used tangle nets or "dillies" (a fine meshed, cone-shaped apparatus that relies on entanglement to capture crabs as they attempt to access the bait) that are also likely to have a marked ghost fishing potential although this was not quantified as part of this research. The concentration of recreational effort in embayment areas such as Moreton Bay and Hervey Bay indicates that ghost fishing by recreational fishing gear may be of a much lower magnitude than that of the commercial fishery, given that approximately 200 tonnes of $P$. pelagicus are caught annually by recreational fishers whose CPUE is considerably less than the commercial fishery (Sumpton et al., 1999). Recreational trapping apparatus are not regularly left in the water overnight and therefore are less likely to be lost compared to commercial apparatus. Results of the commercial pot fisher questionnaire suggest that commercial pot crabbers lose on average 35 pots per year (Sumpton et al., 2003). Given that commercial crabbers report a large proportion of their pot losses are due to theft, fishers report that about $50 \%$ of lost pots remain in the environment. There are approximately 180 fishers in Queensland reporting pot catches of $P$. pelagicus but many of these are only small operators who may not fish for more than a few weeks a year. The actual numbers of pots lost in the environment therefore could range from approximately 1000 to 6000 per year (although the higher figure assumes that all fisher's pot losses remain in the environment).

As to the length of time that a lost pot remains viable, Matsuoka et al. (2005) state that the function of ghost fishing for traps may decline with time. Fishers now use pots incorporating trawl mesh because the nature of the synthetic material leads to little degradation over time, resulting in a pot with a relatively long fishing life. However, such a pot will persist for a considerably longer period in the environment, compared to a traditional wire mesh pot, once lost. Although we have no scientific evidence, fishers believe that the trawl mesh could persist for at least 5, and up to 10, years. Estimates of the time that lost collapsible trawl mesh pots would ghost fish are determined by the life of the metal frame that supports the trawl mesh. Depending on the thickness of the metal rod used for construction, fishers estimate that some pots may continue to ghost fish for more than 4 years before the frame rusts and the pot collapses. For example, larger ( $1.5 \mathrm{~m}$ diameter), more robust collapsible trawl mesh pots are now used in the offshore $P$. pelagicus pot fishery, that utilise $12 \mathrm{~mm}$ galvanised steel rings. The potential for the offshore pots to persist longer in the environment is compounded by the fact that the fishery occurs in offshore waters, with pots generally taking longer to break down in deeper water (Matsuoka et al., 2005).

The elimination or reduction in ghost fishing has been shown to greatly enhance the sustainability of crab fisheries. For example, Yeon et al. (2007) have modelled a 14\% increase in catch if ghost fishing was eliminated from the Korean Portunus trituberculatus fishery. The figures of potential loss to the P. pelagicus fishery by ghost fishing derived from the current study are significant and steps should be taken by the managers of the fishery to reduce the effect of ghost fishing. This can be achieved by using techniques and fishing strategies that reduce gear loss or by using gears that have a lesser potential to ghost fish if they are lost. There is a range of construction alternatives that could minimise the ghost fishing potential of trawl mesh pots in the P. pelagicus fishery. Firstly, an increase in the mesh size (as is already used by some fishers) would limit the number of small animals that are trapped in lost pots. This could be achieved without impacting on the catch rate of legal-sized ( $11.5 \mathrm{~cm}$ carapace width) $P$. pelagicus. We have shown that the larger mesh in the traditional wire mesh pots reduced the amount of bycatch retained in the pots, thereby reducing this potential source of attraction to pots for P. pelagicus. The use of rubber and thin mild steel to construct the support mechanisms of entrance funnels would limit ghost fishing as these components quickly wear and/or corrode, thus collapsing the funnel and preventing the entrance of animals. While the pot would still persist in the environment its potential to ghost fish would be greatly reduced. Designs used by some fishers do already incorporate funnel designs that will collapse within 12 months of pots being lost and management agencies should ensure that these modifications are encouraged.

The use of escape vents, which allow smaller crabs to escape, could alleviate the affect of ghost fishing (Pecci et al., 1978; Smolowitz, 1978b), but would not prevent the ghost fishing of larger, mostly legal-sized, crabs from being caught. The incorporation of biodegradable mesh panels in contemporary trawl mesh pots would reduce the longevity of the pots and reduce their ghost fishing potential. Scarsbrook et al. (1988) used cotton butchers twine to lace patches of mesh into sablefish (Anoplopoma fimbria) traps during an experiment in Canada. The butchers twine reached $0 \mathrm{~kg}$ breaking strain within 31 days, allowing the panels to break away and allow the escape of up to $100 \%$ of captured sablefish. This is a simple, low cost measure that could easily be incorporated into a trawl mesh pot, significantly reducing its potential to ghost fish. Both Scarsbrook et al. (1988) and Smolowitz (1978b) state that the use of corroding or degradable latches on mesh panels may also be an effective option, however, we feel any options that fishery managers apply to mitigate ghost fishing should be cost effective, user friendly and easy to police by enforcement agencies.

\section{Acknowledgements}

We gratefully acknowledge the assistance of Mark Tonks, Shane Gaddes and Brett Davidson in the field. Dr. Tony Courtney and Dr. Ian Brown provided advice of drafts of this manuscript and Andrew Prosser provided assistance during the write-up. An anonymous reviewer greatly improved the original manuscript and we thank them for the critique. We gratefully acknowledge the support of the Fisheries Research and Development Corporation (FRDC Project Number 1998/117) and the Queensland Department of Primary Industries and Fisheries, who funded this work.

\section{References}

Breen, P.A., 1978. Mortality of Dungeness crabs caused by lost traps in the Fraser River estuary British Columbia. N. Am. J. Fish. Manage. 7, 429-435.

Bullimore, B.A., Newman, P.B., Kaiser, M.J., Gilbert, S.E., Lock, K.M., 2001. A study of catches in a fleet of "ghost-fishing" pots. Fish. Bull. 99, 247-253.

Godøy, H., Furevik, D.M., Stiansen, S., 2003. Unaccounted mortality of red crab (Paralithodes camtschaticus) in deliberately lost pots off Northern Norway. Fish. Res. 64, 171-177.

Guillory, V., 1993. Ghost fishing by blue crab traps. N. Am. J. Fish. Manage. 13, 459-466.

Guillory, V., Hein, S., 1998. An evaluation of square and hexagonal mesh blue crab traps with and without escape rings. J. Shellfish Res. 17, 561-562.

Guillory, V., Prejean, P., 1997. Blue crab, Callinectes sapidus, trap selectivity studies: mesh size. Mar. Fish. Rev. 59, 29-32.

Hébert, M., Miron, G., Moriyasu, M., Vienneau, R., DeGrace, P., 2001. Efficiency and ghost fishing of snow crab (Chionoecetes opilio) traps in the Gulf of St. Lawrence. Fish. Res. 52, 143-153. 
Higgs, J., McInnes, K., 2003. 2001 Biennial recreational fishing survey of Queensland residents. Queensland Department of Primary Industries Report, ISSN 07276273.

High, W.L., 1976. Escape of Dungeness crabs from pots. Mar. Fish. Rev. 38, 19-23.

High, W.L., Worlund, D.D., 1979. Escape of king crab, Paralithodes camtschatica, from derelict pots. NOAA Technical Report SSRF-734, 1-11.

Kailola, P.J., Williams, M.J., Stewart, P.C., Reichelt, R.E., McNee, A., Grieve, C., 1993. Australian Fisheries Resources. Bureau of Resource Sciences. Department of Primary Industries and Energy, and The Fisheries Research and Development Corporation, Canberra, Australia.

Kimker, A., 1994. Tanner crab survival in pots. Alaska Fish. Res. Bull. 1, 179-183.

Matsuoka, T., Nakashima, T., Nagasawa, N., 2005. A review of ghost fishing: scientific approaches to evaluation and solutions. Fish. Sci. 71, 691-702.

Miller, R.J., 1978. Saturation of crab traps: reduced entry and escapement. J. Cons. int. Explor. Mer 38, 338-345.

Miller, R.J., 1980. Design criteria for crab traps. J. Cons. Int. Explor. Mar. 39, 140-147.

Muir, W.D., Durkin, J.T., Coley, T.C., McCabe Jr., G.T., 1984. Escape of captured Dungeness crabs from commercial crab pots in the Columbia River estuary. N. Am. J. Fish. Manage. 4, 552-555.

Pecci, K.J., Cooper, R.A., Newell, C.D., Clifford, R.A., Smolowitz, R.J., 1978. Ghost fishing of vented and unvented lobster, Homarus americanus, traps. Mar. Fish. Rev. 40, $9-43$.

Scarsbrook, J.R., McFarlane, G.A., Shaw, W., 1988. Effectiveness of experimental escape mechanisms in sablefish traps. N. Am. J. Fish. Manage. 8, 158-161.

Smith, G.S., Sumpton, W.D., 1989. Behaviour of the commerical sand crab Portunus pelagicus (L.) at trap entrances. Asian Fish. Sci. 3, 101-113.

Smolowitz, R.J., 1978a. Trap design and ghost fishing: an overview. Mar. Fish. Rev. 40, 2-8.
Smolowitz, R.J., 1978b. Trap design and ghost fishing: Discussion. Mar. Fish. Rev. 40, 59-67.

Sumpton, W., Gaddes, S., McLennan, M., Campbell, M., Tonks, M., Good, N., Hagedoorn, W., Skilleter, G., 2003. Fisheries biology and assessment of the blue swimmer crab (Portunus pelagicus) in Queensland. Final Report to FRDC on Project No. 98/117. Department of Primary Industries and Fisheries, Brisbane, Australia, p. 156. http://www2.dpi.qld.gov.au/far/14777.html.

Sumpton, W. Gaddes, S., McLennan, M.F., 1999. Blue swimmer crab fishery in Queensland-summary of changes 1984-1998. Queensland Department of Primary Industries Report Series, Brisbane.

Vazquez Archdale, M., Anasco, C.P., Hiromori, S., 2006. Comparative fishing trials for invasive swimming crabs Charybdis japonica and Portunus pelagicus using collapsible pots. Fish. Res. 82, 50-55.

Vazquez Archdale, M., Anasco, C.P., Kawamura, G., Tomiki, S., 2007. Effect of two collapsible pot designs on escape rate and behviour of the invasive swimming crabs Charybdis japonica and Portunus pelagicus. Fish. Res. 85, 202-209.

Vazquez Archdale, M., Kuwahara, O., 2005. Comparative fishing trials for Charybdis japonica using collapsible box-shaped and dome-shaped pots. Fish. Sci. 71, 1229-1235.

Yeon, I., Song, M.Y., Shon, M.H., Hwang, H.J., Im, Y.J., 2007. Possible new management measures for stock rebuilding of blue crab, Portunus trituberculatus (Meirs), in western Korean waters. In: The Changing North Pacific: Previous Patterns, Future Projections and Ecosystem Impacts. PICES Annual Meeting, Victoria, Canada, October 26-November 5.

Zhou, S., Shirley, T.C., 1997. Performance of two red king crab pot designs. Can. J. Fish. Aquat. Sci. 54, 1858-1864. 